\title{
Accountability: já podemos traduzi-la para o português?*
}

\author{
José Antonio Gomes de Pinho** \\ Ana Rita Silva Sacramento***
}

Sumário: 1. Introdução; 2. Compreendendo a accountability; 3. Assim caminha o Brasil; 4. E afinal, podemos traduzir accountability?

Summary: 1. Introduction; 2. Understanding accountability; 3. The Brazilian way; 4. Can we finally translate accountability?

Palavras-chave: accountability; democracia; Estado brasileiro.

KEY worDs: accountability; democracy; Brazilian state.

O objetivo principal deste artigo é verificar se as alterações políticas, sociais e institucionais (ocorridas no Brasil) contribuíram para que a tradução da palavra accountability germinasse no solo brasileiro, tendo transcorrido duas décadas desde a publicação do instigante artigo de Anna Maria Campos sobre a ausência desse conceito no Brasil. Trata-se de estudo de natureza exploratória, analítica e descritiva, numa abordagem essencialmente qualitativa, em que se procurou, além de compreender o significado da palavra accountability nos dicionários e nos trabalhos sucessivos ao de Campos, analisar, por meio da literatura especializada, as principais mudanças processadas no cenário brasileiro, especialmente quanto à organização da sociedade, descentralização e transparência governamental e quanto à emergência de novos valores sociais em substituição aos tradicionais. Reconhecendo que avanços têm sido

\footnotetext{
* Artigo recebido em mar. e aceito em set. 2009.

$* *$ Doutor em planejamento regional pela University of London (LSE), professor associado I da Universidade Federal da Bahia (UFBA), coordenador do Núcleo de Pós-Graduação da Escola de Administração da UFBA. Endereço: Universidade Federal da Bahia, Escola de Administração. Av. Reitor Miguel Calmon, s/n, Vale do Canela - CEP 40110-100 — Salvador, BA, Brasil. E-mail: jagp@ufba.br.

*** Doutoranda pela Escola de Administração da UFBA (EA/UFBA), mestre em administração pela EA/UFBA, coordenadora do curso de administração da Faculdade Anísio Teixeira. Endereço: Faculdade Anísio Teixeira de Feira de Santana. Rua Juracy Magalhães, 222 - Ponto Central — CEP 44032-620, Feira de Santana, BA, Brasil. E-mail: anasacramentos@hotmail.com.
} 
realizados nessa direção, admite-se ser difícil dar uma resposta conclusiva à questão formulada. Considera-se que estamos mais perto da resposta do que quando Campos se defrontou com o problema, mas ainda muito longe de construir uma verdadeira cultura de accountability.

\section{Accountability: can we now translate it into Portuguese?}

The main purpose of this article is to see whether the political, social and institutional changes that took place in Brazil in the last years have contributed to give a meaning to the term accountability, after two decades since Anna Maria Campos published an interesting paper about the absence of this concept in the country. The article presents an exploratory, analytical and descriptive study, carried out under a qualitative methodology, which, besides researching the meaning of accountability in dictionaries and subsequent papers to the study by Campos, analyzed in the specialized literature the main changes that occurred in the Brazilian society in relation to its organization, as well as decentralization, government transparency and the emergence of new social attitudes in place of traditional values. Although there has been some progress, it is still very difficult to reach a conclusive answer for this question. The answer is closer than it was when Campos first searched for it, but we are still far from building a comprehensive accountability culture.

\section{Introdução}

Vinte anos se passaram desde que Anna Maria Campos expôs sua angústia sobre a ausência do conceito e, consequentemente, de uma palavra que, no dicionário da língua portuguesa, traduzisse com perfeição o significado de accountability. ${ }^{1} \mathrm{Na}$ oportunidade, a estudiosa indicou que a possibilidade de tornar a administração pública brasileira accountable estava diretamente relacionada às chances das seguintes ocorrências, as quais, como podem ser verificadas, guardam certa interdependência e estão diretamente relacionadas à democracia: a) organização dos cidadãos para exercer o controle político do governo; b) descentralização e transparência do aparato governamental; e c) substituição de valores tradicionais por valores sociais emergentes (Campos, 1990:48).

\footnotetext{
${ }^{1} \mathrm{O}$ artigo de Anna Maria Campos, embora publicado na RAP de 1990 (fev./abr.), foi produzido em 1987, período no qual a Constituição Federal do Brasil estava em elaboração, e publicado originalmente em 1988 na coletânea Public service accountability: a comparative perspective.
} 
Aliás, a angústia de Campos é ainda mais antiga, pois, como ela mesma relata, se iniciou em 1975, período em que cursando o master of public administration, nos EUA, ouviu pela primeira vez a palavra accountability. Como se sabe, naquele período se vivia no Brasil o auge da ditadura, terreno infértil para brotar qualquer accountability e onde a primazia era a luta contra o estado autoritário. Quando a autora finalmente conclui seu trabalho, em 1988, o qual geraria a publicação do famoso artigo no Brasil em 1990, o país desfrutava de ventos mais democráticos, uma vez que o regime militar já havia sido encerrado, mas muito longe ainda de qualquer prática efetiva de accountability, conforme demonstrou seu estudo.

Observa-se, desde então, que o cenário político brasileiro mudou substancialmente: uma nova Constituição Federal foi elaborada, a democracia se consolidou e reformas no aparelho do Estado foram empreendidas com a promessa de tornar a administração pública mais eficiente e, inclusive, mais controlável. Paralelamente, no meio acadêmico, uma imensa literatura tem sido produzida no intuito de analisar e compreender os impactos de tais mudanças no tecido social, bem como suas contribuições para viabilizar pelo menos uma aproximação do conteúdo do conceito da accountability com a realidade da administração pública brasileira. Nesses estudos, a palavra accountability tem sido comumente traduzida como "responsabilização".

Conhecer se o caminhar brasileiro está levando à aproximação do conceito da accountability, se efetivamente já podemos traduzir o termo para o português, é a motivação básica deste estudo, que se inspira óbvia e explicitamente no trabalho de Campos, inclusive no próprio título, e para o qual se estabeleceu como ponto de partida o seguinte problema: as alterações políticas, sociais e institucionais, ocorridas nos últimos 20 anos, contribuíram para que a tradução da palavra accountability germinasse no solo brasileiro? Procura-se fazer, especificamente, um cotejamento do significado da palavra accountability oferecida por Campos e outros autores com as mudanças políticas, sociais e institucionais verificadas no Brasil nas duas últimas décadas.

$\mathrm{O}$ trabalho está dividido em três seções, além da introdução. Na primeira seção efetua-se uma análise do significado da accountability. Na segunda, alguns trabalhos sobre a realidade brasileira são analisados e distribuídos em três subseções, de acordo com o que Campos (1990) estabeleceu como possibilidades de estímulos para o desenvolvimento da accountability no Brasil, a fim de fornecer um retrato sobre a caminhada realizada ao longo desses 20 anos. Assim, trabalhos sobre a organização da sociedade civil são analisados com o propósito de relacioná-los com a organização dos cidadãos para exercer o controle político do governo. Para a descentralização e transparência do 
aparato governamental são buscados indícios nos trabalhos que analisam as mudanças introduzidas após a reforma do aparelho do Estado, empreendida a partir de 1995. Por fim, para saber se há substituição de valores tradicionais por valores sociais emergentes são buscadas informações através dos autores que analisam a cultura política brasileira. Finalmente, na terceira seção, são apresentadas as considerações finais e limitações do estudo.

\section{Compreendendo a accountability}

A compreensão do conceito da accountability é o grande objetivo desta seção que, para tanto, subdivide-se em duas subseções. Inicialmente (e já que existem tantas dificuldades de entendimento do termo em português) esforços são empreendidos no sentido de conhecer o termo accountability tal qual exposto em dicionários. Em seguida, os ensinamentos de Campos são cotejados com trabalhos mais recentes a fim de possibilitar uma reflexão a respeito da evolução do seu significado.

\section{Buscando a compreensão por meio dos dicionários}

Tendo em vista que em muitos trabalhos acerca de accountability são observadas referências sobre a dificuldade de traduzir o mencionado termo, adota-se o pressuposto de que não existe mesmo uma palavra única que o expresse em português. ${ }^{2} \mathrm{O}$ que se percebe são "traduções" diferentes para o termo por parte de vários autores, ainda que os termos produzidos possam estar próximos ou convergentes. Em síntese, não existe perfeita concordância nas traduções. Desse modo, julgou-se importante, assim como fez Campos, buscar, inicialmente, o significado da accountability a partir do que está exposto em dicionários da língua na qual ela se originou, a inglesa, para, em seguida, verificar sua tradução em dicionários do tipo "inglês-português".

Cumpre informar, e isto foi uma surpresa, que não são todos os dicionários de inglês que apresentam a palavra. Assim, para maior segurança e conforto, buscou-se também termos correlatos, como accountable. Destaque-

\footnotetext{
${ }^{2}$ De grande importância notar que em outros trabalhos, ao contrário, muitos autores assumem uma tradução do termo sem maiores questionamentos, o que nos leva a especular que ou eles têm muita segurança com a tradução adotada, ou simplesmente não querem entrar nessa discussão.
} 
se que, obviamente, não se pretende esgotar as opções de consulta, mas identificar algumas fontes que possam ajudar no entendimento do termo.

De acordo com o descrito no Oxford advanced learner's dictionary (2005:10): "Accountable: responsible for your decisions or actions and expected to explain them when you are asked: Politicians are ultimately accountable to the voters".

Nessa fonte não se encontra uma explicação direta do que accountability representa, sendo citado apenas um exemplo de sua aplicação: "the accountability of a company's directors to the shareholders".

No Merriam-Webster's collegiate dictionary (1996:08): "Accountability (1794): the quality or state of being accountable; an obligation or willingness to accept responsibility or to account for one's actions".

Verifica-se, pois, que a ideia contida na palavra accountability traz implicitamente a responsabilização pessoal pelos atos praticados e explicitamente a exigente prontidão para a prestação de contas, seja no âmbito público ou no privado. Constatou-se ainda quão antiga é essa palavra nesse idioma, pois desde 1794 ela consta no dicionário. Em outras palavras, se na realidade brasileira esse termo não tem existência no final do século $\mathrm{XX}$, na realidade inglesa do final do século XVIII ele aparece. Especulando, podemos associar o aparecimento do termo na realidade inglesa com a emergência do capitalismo e, portanto, da empresa capitalista a ser gerida de acordo com os parâmetros desse sistema e de uma moderna administração pública rompendo com os referenciais do patrimonialismo.

Consultando o Roget's thesaurus (1962:366), accountability mostra-se identificada com dueness, que se associa também com onus, responsability, obligation e com duty, que se associa com obligation, liability, onus, responsability. Sendo liability a palavra de entendimento mais difícil em português, buscou-se sua tradução. Encontrou-se o adjetivo liable for: responsible according to law. Partiu-se para outra fonte, o Learner's dictionary of current english e não foi encontrada a palavra accountability, apenas accountable: able to $s b / f o r$ sth, responsible; expected to give an explanation. Por fim, na busca empreendida nos dicionários de inglês-português, verificamos que em Vallandro e Vallandro (s.d.) também não aparece o termo procurado, mas accountable: "responsável frente à alguma coisa: sujeito à prestar contas". No Michaelis dicionário prático (1988:03), a palavra foi localizada apresentando o substantivo responsabilidade como seu correspondente no português. Para a tradução de accountable, o Michaelis indica três adjetivos: 1. responsável; 2. explicável; e 3. justificável. 
Claro está, portanto, que, de acordo com as fontes consultadas, não existe um termo único em português que defina a palavra accountability, havendo que trabalhar com uma forma composta. Buscando uma síntese, accountability encerra a responsabilidade, a obrigação e a responsabilização de quem ocupa um cargo em prestar contas segundo os parâmetros da lei, estando envolvida a possibilidade de ônus, o que seria a pena para o não cumprimento dessa diretiva.

\section{Buscando a compreensão por meio dos argumentos de Campos e posteriores}

O objetivo deste trabalho, no momento, é enriquecer o conceito com contribuições de autores pós-Campos. Interessante notar que Schedler (1999:13) observa que o significado de accountability permanece subexplorado. Para esse autor, muito embora em todo o mundo instituições financeiras, líderes de partidos, ativistas de bases, jornalistas e cientistas políticos tenham descoberto as bênçãos e aderido à causa da accountability pública, o seu significado permanece evasivo, com fronteiras indefinidas e estrutura interna confusa. Tal afirmação, de certa forma, minimiza o desconforto exposto por Campos (1990) e por todos os brasileiros que se lançaram na busca incessante da sua tradução. Evidentemente, os conceitos estão em permanente construção e evolução, uma vez que não ficam congelados, pois à medida que a realidade social muda, eles também devem se adequar, se qualificar, mas a observação de Schedler parece expressar que o conceito, mesmo na realidade anglo-saxã, também não é tão preciso assim.

Como se sabe, o ponto de partida para Campos (1990) compreender o significado de accountability foi a obra de Frederich Mosher (Democracy and the public service) publicada em 1968. É daí que a autora extrai elementos para afirmar que a accountability é sinônimo de responsabilidade objetiva, isto é, trata-se da responsabilidade de uma pessoa ou organização perante outra, fora de si mesma. Tal responsabilidade tem consequências, implicando em prêmios, pelo seu cumprimento, e castigos, quando o inverso é verificado. Para Mosher (apud Campos, 1990:33), "quem falha no cumprimento de diretrizes legítimas é considerado irresponsável e está sujeito a penalidades". Vê-se, portanto, que quem tem responsabilidade para com algo, ou alguém, também deve estar sujeito à responsabilização pelo desempenho e resultados de suas ações.

Trosa (2001:264) alerta para a necessidade de uma visão moderna de responsabilidade, tendo em vista que esta não pode ter como base a ameaça e 
a sanção, mas um sentimento interiorizado que "cada um faz parte da solução e não apenas do problema". Essa acepção, que é muito nobre, está associada à ideia da responsabilidade subjetiva, isto é, à cobrança que a pessoa exerce sobre si mesma quanto à necessidade de prestar contas a alguém. Mas Campos (1990) e, mais tarde, Przeworski (1998) e Melo (2007) nos levam a refletir a partir de Madison: "Se os homens fossem anjos, não seria necessário haver governos. Se os homens fossem governados por anjos, dispensar-se-iam os controles internos e externos" (Madison, 1982 [1788] apud Melo, 2007:12).

Verifica-se que o caráter da obrigatoriedade em prestar contas dos atos praticados e da aplicação de penalidades pelos deslizes eventualmente constatados é muito caro ao termo sob estudo. Leciona, por exemplo, Przeworski (1998:61) que os governos são accountable se os cidadãos têm como saber se aqueles estão ou não estão atuando na defesa dos interesses públicos e podem lhes aplicar as sanções apropriadas, de tal modo que os políticos que atuarem a favor dos interesses dos cidadãos sejam reeleitos e os que não o tenham feito percam as eleições. Destaque-se também que na concepção da accountability construída por Schedler (1999) três questões são identificadas como necessárias para sua eficácia: informação, justificação e punição. Nessa concepção, as duas primeiras questões - informação e justificação - remetem-nos ao que o autor denomina de answerability, isto é, a obrigação dos detentores de mandatos públicos informarem, explicarem e responderem pelos seus atos. A última — punição - diz respeito à capacidade de enforcement, ou seja, a capacidade das agências de impor sanções e perda de poder para aqueles que violarem os deveres públicos. Constata-se, mais uma vez, que a accountability implica em mais do que geração de dados e interação de argumentos, visto que inclui, também, a possibilidade de punir comportamento inadequado. Ainda de acordo com esse autor, exercícios de accountability que expõem delitos sem a imposição de penalidades aparecerão como fracas e diminuídas formas de accountability.

Pode-se concluir, diante do exposto, que tanto o pensamento de Przeworski (1998) quanto o de Schedler (1999) contribuíram para que o de Mosher, apresentado por Campos em 1988, ficasse mais claro, compreensível. O caráter bidimensional da accountability apresentado por Schedler, por exemplo, funciona como um recurso didático porque ajuda a visualizar o processamento da accountability no tempo. Pode-se afirmar que esse tempo se constitui em um ciclo dividido em duas partes, ou seja, em dois momentos distintos, porém complementares: o momento da answerability e o momento do enforcement. Necessário, pois, que estes se juntem para que se possa afirmar que o processo se completou. Resumidamente, podemos afirmar ainda 
que accountability nasce com a assunção por uma pessoa da responsabilidade delegada por outra, da qual se exige a prestação de contas, sendo que a análise dessas contas pode levar à responsabilização. Representando-a, ainda que num esquema bem simples, temos: "A" delega responsabilidade para "B" $\rightarrow$ "B", ao assumir a responsabilidade, deve prestar contas de seus atos para "A" $\rightarrow$ "A" analisa os atos de "B" $\rightarrow$ feita tal análise, "A" premia ou castiga "B".

Nesse ponto, considera-se importante destacar que um dos primeiros resultados das reflexões de Campos foi o de relacionar accountability com democracia (1990:33), considerando que é maior o interesse pela accountability em sociedades que apresentam avançado estágio democrático. Mais tarde, Schedler (1999) vai reconhecer que o significado da accountability é antagônico ao poder monólogo, o que contribui para reforçar a ideia anteriormente apresentada sobre a responsabilidade objetiva, exigida de fora, tornado necessário o estabelecimento de um diálogo entre os atores responsáveis e os responsivos. Esse autor ressalta que a verdadeira razão de ser da accountability reside na pressuposição da existência do poder e, nesse sentido, o seu principal objetivo não é eliminá-lo, mas controlá-lo. De fato, como pensar em exigir prestação de contas em regimes ditatoriais, nos quais a liberdade de expressão é tolhida e os dirigentes não são delegados "no" poder, mas usurpadores "do" poder? Conclui-se, portanto, que o controle da atividade estatal deve ser visto como um dos eixos que dão sustentação ao regime democrático.

Outro estudo que merece ser destacado para a compreensão da accountability é o oferecido por O'Donnell $(1998,1991)$. O autor também enxerga a accountability como bidimensional, mas, dessa feita, a classificação ocorre de acordo com o lugar ocupado pelos atores que participam do processo, sendo, nesse caso, as dimensões denominadas vertical e horizontal. Na concepção de O'Donnell, que poderia ser considerado um autor "nacional" por sua vinculação com o Brasil, escrevendo entre 1988 e 1991, quando a redemocratização engatinhava, as ações realizadas individualmente e/ou coletivamente, com referência aos que, eleitos ou não, exercem posições em instituições do Estado, fazem parte da accountability vertical, ao passo que as agências estatais possuidoras de direito, poder legal, disposição e capacidade para realizar ações, que vão desde a supervisão de rotina e sanções legais ou até o impeachment contra ações ou omissões de outros agentes ou agências do Estado que possam ser qualificadas como delituosas, fazem parte da accountability horizontal. Destacam-se, como principais integrantes da primeira dimensão, segundo o autor, as eleições, as reivindicações sociais livremente proferidas e a atuação da mídia divulgando tais reivindicações — ao menos as mais visíveis - e os atos supostamente ilícitos de autoridades públicas. E, como mecanis- 
mos da segunda dimensão, as instituições clássicas das poliarquias, a saber: o Executivo, o Legislativo, o Judiciário, as agências de supervisão e as instâncias responsáveis pela fiscalização das prestações de contas. Conclui-se, portanto, que, na concepção desse autor, enquanto a dimensão vertical pressupõe uma ação entre desiguais - cidadãos versus representantes - a dimensão horizontal pressupõe uma relação entre iguais — checks and balances entre os poderes constituídos.

O'Donnell (1998) destaca que ainda que tais mecanismos de accountability estejam implantados na América Latina, estes exibem alta fragilidade. No plano vertical, embora admitindo as eleições como seu canal principal, o autor reconhece que, pelo fato destas somente ocorrerem de tempos em tempos, em adição à existência de sistemas partidários pouco estruturados, a alta volatilidade de eleitores e partidos, temas de políticas públicas pouco definidas e reversões políticas súbitas, a eficácia da accountability eleitoral torna-se bastante fragilizada. De acordo com ele, "a votação retrospectiva que toma informações apenas no desempenho passado do candidato não é suficiente para induzir os governos a atuarem responsavelmente" (Przeworski e Stokes apud O'Donnell 1998:29). As limitações das eleições também são admitidas por Bobbio (apud Przeworski, 1998:66), uma vez que no seu entendimento estas permitem apenas que os cidadãos ratifiquem ou rejeitem, de tempos em tempos, as decisões tomadas pelas equipes formadas por seus representantes. A análise de Campos (1990) sobre o processo eleitoral brasileiro é ainda mais desalentadora, uma vez que o caráter episódico das eleições se agrava com o fato de que muitos eleitores barganham os seus votos.

A eficácia dos demais mecanismos de accountability vertical — as reivindicações sociais e atuação da mídia - também é questionada por O’Donnell (1998), quando este considera que a mídia, agindo parcialmente ao denunciar possíveis delitos, nomeando os supostos responsáveis, contribui para que algumas autoridades corruptas sejam poupadas, enquanto inocentes são condenados pela opinião pública. Mais uma vez, verifica-se que Campos (1990:39) também chamou a atenção para a limitação desse mecanismo no Brasil, considerando-o "subserviente a interesses e conveniências particulares", portanto, sem liberdade para poder agir como uma instituição vigilante. Tal análise não nos surpreende, pois Campos "olhava" para uma imprensa recém-saída do regime militar, em que a capacidade de crítica era bastante reduzida.

Com referência à dimensão horizontal, O'Donnell considera que sua efetividade depende não apenas de agências isoladas lidando com questões específicas, mas com uma rede dessas agências, uma vez que normalmente as decisões são tomadas pelos tribunais ou, em caso de impeachment, pelos 
legisladores. O’Donnell (1998) reconhece, ainda, a possibilidade de violação da accountability horizontal através da usurpação ilegal da autoridade de uma agência estatal por outra e da corrupção, que consiste na obtenção de vantagens ilícitas por uma autoridade pública para si ou para aqueles de alguma maneira ligados a ela. Verifica-se que tal dimensão não escapou à análise de Campos sobre a realidade brasileira do final da década de 1980. Para ela, faltava credibilidade ao Poder Legislativo, cujos "representantes" não sendo pressionados a cumprir as promessas de campanha preocupavam-se apenas com os seus interesses pessoais e as conveniências de seus parentes e amigos (Campos, 1990:39). A autora considerava ainda que o cidadão brasileiro pouco podia esperar do Judiciário, poder dependente do Executivo, inclusive para obtenção de recursos financeiros. Esse cenário de "debilidade das instituições", em adição ao baixo nível de organização da sociedade civil, é o que explica, segundo Campos, a má qualidade do processo de informações entre governo e sociedade, e que permitiu a supremacia do Executivo federal sobre os níveis estaduais e municipais, bem como sobre os poderes Legislativo e Judiciário no Brasil. Nas palavras da autora, "imune a controles externos, a burocracia pública é corrupta e ineficiente, enquanto os cidadãos continuam sem qualquer proteção contra as decisões arbitrárias" (Campos, 1990:42).

Importante ressaltar que, de acordo com a literatura pesquisada, reduzir a assimetria informacional entre governo e cidadãos não é uma tarefa simples. Para Przeworski (1998:67), mesmo que todas as instituições democráticas clássicas estejam funcionando bem, elas não são suficientes para garantir a accountability e para capacitar os cidadãos a obrigarem os governos a cumprir com o seu dever, pois estes sempre terão informações privadas sobre seus objetivos e sobre as relações entre as políticas e seus resultados. $\mathrm{O}$ autor sugere então que sejam criadas instituições independentes de outros órgãos do governo e que ofereçam aos cidadãos as informações necessárias para que estes aperfeiçoem sua avaliação $a$ posteriori dos atos do governo e não apenas dos resultados. Schedler (1999) também reconhece que, dada à assimetria entre atores estatais e não estatais, é fictício um cenário em que o controle de poder é perfeito. Constata-se que esses autores adotam a assimetria informacional como uma premissa praticamente inquestionável na relação governo/cidadãos.

O Centro Latino-Americano de Administração para o Desenvolvimento (Clad) alertou, mais recentemente, para o fato de que a realização do valor político da accountability depende de dois fatores: um deles é o desenvolvimento da capacidade dos cidadãos de agir na definição das metas coletivas de sua sociedade, já que uma população indiferente à política inviabiliza tal 
processo; o outro é a construção de mecanismos institucionais que garantam o controle público das ações dos governantes ao longo de todo o seu mandato (2006:27). Como se vê, o alerta do Clad guarda estreita relação com o que Campos (1990) denominou como sementes necessárias para o florescer da accountability no Brasil. Naquela oportunidade, Campos (1990:35-37) destacou que não haveria condição para a accountability enquanto o povo se definisse como tutelado e o Estado como tutor. Ademais, considerava ainda essa autora que a virtual ausência do conceito de accountability no Brasil decorre da sua "pobreza política", uma vez que as pessoas optam por esperar que o Estado defenda e proteja os interesses não organizados, ao invés de atuar na organização para agregação de seus próprios interesses ou para enfrentamento do poder do Estado.

Convém destacar ainda que o Clad (2006) identifica cinco formas de avaliação da administração pública, nas quais fica evidenciado, mais uma vez, o caráter multidimensional da accountability: a) pelos controles clássicos; b) pelo controle parlamentar; c) pela introdução lógica dos resultados; d) pela competição administrada; e e) pelo controle social. Pode-se compreender, através dessas formas, que a novidade em relação às formas anteriormente citadas situa-se nas alíneas "c", introdução lógica dos resultados; "d", competição administrada; e "e", controle social. Tais formas se relacionam com o paradigma da nova gestão pública, sendo que na introdução lógica dos resultados considera-se fundamental a utilização de sistemas de avaliação ex post das políticas públicas como meio para medir seu desempenho e exigir a prestação de contas dos funcionários responsáveis, tanto por sua execução quanto pelos resultados obtidos. Trata-se, pois, do confronto entre metas estabelecidas e resultados obtidos. Na forma definida por competição administrada, o leque de provedores de serviços é ampliado para que a dinâmica da competição se estabeleça entre os provedores, uma vez que nesse paradigma se considera que o monopólio na prestação dos serviços públicos é ineficaz. De acordo com Abrúcio (2006), a lógica da competição administrada sinaliza, por meio dos custos e da qualidade, quem deve ser premiado ou qual organismo requer reformulações. Por fim, no controle social, os cidadãos se tornam controladores dos governantes não apenas nas eleições, mas ao longo do mandato de seus representantes. Para tanto, de acordo com Grau (2006:276), uma série de condições precisa ser atendida, pois o controle social deve ser aplicado tanto na esfera das decisões de políticas públicas (o núcleo estratégico da administração pública) como também na esfera da produção de bens e serviços públicos, inclusive nos que foram privatizados. 
Depreende-se, diante do exposto, que o estudo sobre a compreensão do significado da accountability tem caráter progressivo, inesgotável. Observase que, quando Campos pensou e escreveu havia um determinado contexto (1975-1987): regime militar, Estado burocrático e início da democratização, e, depois de 1990 (ano da publicação do artigo), o contexto é outro: democratização, Estado neoliberal, globalização e tentativas de implantação do Estado gerencial. Desse modo, os estudos que a sucederam acrescentaram qualificações à palavra, evidenciando sua elástica capacidade de ampliação para permanecer dando conta daquilo que se constitui na razão de seu surgimento: garantir que o exercício do poder seja realizado, tão somente, a serviço da res publica.

\section{Assim caminha o Brasil}

Objetiva-se, a partir de agora, promover uma reflexão acerca da realidade brasileira, tomando por base autores que analisam algumas mudanças políticas, sociais e institucionais ocorridas no Brasil nos últimos 20 anos, a fim de verificar o vínculo destas com a accountability. Antes, porém, considera-se necessário estudar os marcos legais que as viabilizaram, motivo pelo qual a Constituição Federal de 1988 e a Reforma do Aparelho do Estado de 1995 serão inicialmente destacadas, ainda que de forma panorâmica. Admite-se, pois, que estes se constituem em fundamentos de natureza macro, os quais favoreceram o desencadeamento das demais ações.

A Constituição Federal de 1988 (CF/88) institucionalizou a participação da sociedade na gestão das políticas públicas. Desde então, diversos mecanismos de participação da comunidade na gestão dessas políticas vêm sendo gradativamente implementados. Conselhos, orçamento participativo e plebiscito são alguns exemplos dos mecanismos que podem ser utilizados para efetiva prática dos dispositivos constitucionais. Ademais, de acordo com Mota (2006), a CF/88 apresenta vários dispositivos instrumentais que viabilizam o controle dos atos dos agentes públicos. Destaque-se ainda que, de acordo com a autora, tais dispositivos garantem a publicidade e a transparência dos atos públicos, viabilizam o questionamento em si desses atos e trazem a potencialidade de sanções. Ainda segundo Mota (2006), o advento da CF/88 assegurou o direito à impetração da denominada ação popular, instrumento fundamental para o exercício da accountability, uma vez que, além de viabilizar a defesa dos interesses públicos, destaca a possibilidade de o cidadão comum agir em defesa do interesse coletivo. 
Com a publicação do Plano Diretor de Reforma do Aparelho do Estado, em 1995, e a consequente adoção do paradigma da administração gerencial em substituição ao burocrático, a necessidade de mecanismos para o exercício do controle social no Brasil ganhou especial notoriedade. Desde então, o foco do controle, que no modelo anterior se dava nos procedimentos, deslocou-se para o resultado. Para Bresser-Pereira (2006), os controles sociais são essenciais na administração pública gerencial, na medida em que compensam a redução do controle legal de procedimentos e complementam o controle de resultados. O pensamento de Abrúcio (2006) vai ao encontro do de BresserPereira, pois considera que formas de responsabilização baseadas no desempenho governamental e na participação devem ser incluídas para garantir a maior eficiência dos serviços prestados pelo Estado, bem como a autonomia gerencial dos administradores públicos.

Constata-se, portanto, a existência, no Brasil, de marcos legais que chamam a atenção para a necessidade da criação de mecanismos que possibilitem o exercício do controle político do Estado pelos cidadãos. Logicamente, tudo isso ganhará reforço e possibilidades de concretização se a sociedade civil estiver consciente de seu papel e os esforços forem mobilizados e utilizados com tal propósito.

\section{Sobre a organização da sociedade civil}

Muitos autores reconhecem que em determinados momentos de sua história política a sociedade civil brasileira demonstrou capacidade de organização e reação. Compreendendo sociedade civil como a forma por meio da qual a sociedade se organiza politicamente para influenciar a ação do Estado, Dagnino (2002) destaca o papel fundamental exercido pela sociedade civil brasileira no longo processo de transição democrática, na luta contra o Estado autoritário instalado em 1964. De acordo com a autora, a partir da década de 1980, ocorrência de fenômenos, tais como o aumento do associativismo e a emergência de movimentos sociais organizados, provocaram o ressurgimento da sociedade civil brasileira. De forma similar, outros autores reconhecem que a partir de então, "novos potenciais culturais de construção democrática emergiram e novas práticas, movimentos e instituições tornaram-se possíveis" (Avritzer, 2002:17). Para se ter uma ideia da significância desse momento, Dagnino (2002) sustenta que, para alguns analistas, esse ressurgimento é considerado como a "fundação efetiva da sociedade civil no Brasil". A significância das ações empreendidas por grupos expressivos da sociedade civil (Cebrap, SBPC, 
$\mathrm{OAB}, \mathrm{ABI}, \mathrm{CNBB}$ etc.) nesse momento particular da história política brasileira também é resgatada por Sorj (2006), Santos (2006) e Carvalho (2008). Tais grupos foram capazes de construir uma "aliança de diferentes em função de um projeto político específico: democratizar o País" (Sorj, 2006:60).

Outros feitos podem ser resgatados na história recente da política brasileira para demonstrar o poder organizativo da sociedade civil. O movimento pelas eleições diretas em 1984, por exemplo. Se, infelizmente, como nos lembra Carvalho (2008:204) "as eleições diretas resultaram na escolha de um presidente despreparado, autoritário e messiânico" — Fernando Collor de Mello — o qual mergulhou num verdadeiro mar de denúncias de corrupção, felizmente, esse movimento serviu de aprendizado para a campanha em favor do seu impedimento, outra importante e inédita demonstração de iniciativa cidadã (Carvalho, 2008:193). O exemplo do impedimento de Collor neste trabalho está sendo destacado porque se acredita que este pode ser compreendido como um raro exercício de accountability no Brasil, uma vez que, de acordo com Carvalho (2008), esse fato foi uma vitória cívica importante, pois deu aos cidadãos a sensação inédita de que podiam exercer algum controle sobre os governantes.

Sobre tal questão é salutar destacar ainda as reflexões oferecidas por Sorj (2006) e Santos (2006), os quais reconhecem que alcançada a democracia, a forma de funcionamento e o lugar da sociedade civil no sistema político foram alterados. Para Sorj (2006), os semanários desapareceram; os órgãos de pesquisa não influenciam mais o debate público; a CNBB e as pastorais perderam boa parte de sua importância no cenário político; as organizações profissionais e sindicais passaram a se dedicar basicamente aos assuntos relativos a suas áreas e a seus interesses corporativos. Santos (2006) afirma que o desaparecimento dessas organizações, findo o regime autoritário, ocorreu porque elas passaram a partidos políticos ou a empresas de consultoria, ou de representação de lobbys, ou porque se converteram num novo tipo de organizações, parte maior do terceiro setor, as quais se ocupam "do privado e não do público; do social, não do político; do micro, não do macro (a democracia liberal e o capitalismo neoliberal)" (2006:409). Na crítica formulada por Sorj (2006:61), esse novo tipo de organização se constitui, sociologicamente, como "organizações profissionais, nichos de emprego para ativistas sociais".

Entretanto, torna-se imperioso reconhecer neste estudo que a realidade não nos parece tão desalentadora, afinal já é notório que uma nova safra de organizações tem sido plantada, por iniciativa da própria sociedade, com o propósito de exercer o controle político do governo, algumas atuando em nível local, outras em nível nacional. Algumas organizações de caráter mais geral, como o Instituto Ethos, articulam pactos empresariais com o objetivo de evitar a corrupção (o Pacto pela Integridade e Contra a Corrupção). Outras, 
como a CNBB, não desanimaram e continuam a se envolver diretamente na questão. Aliás, a campanha da fraternidade da CNBB de 1996, cujo tema foi "Fraternidade e Política", é considerada o embrião do Movimento de Combate à Corrupção Eleitoral (MCCE). ${ }^{3}$ Atualmente, tais entidades estão unidas numa campanha denominada "Ficha Limpa", efetuando coleta de assinaturas para a aprovação de um novo projeto de lei de iniciativa popular, elaborado pelo MCCE, que busca impedir tanto a candidatura de pessoas com antecedentes criminais quanto o retorno político dos que renunciam ao mandato para escapar de punições legais. Também é fruto de iniciativa do MCCE a mobilização social que resultou na aprovação do primeiro projeto de iniciativa popular no país convertido na Lei no 9.840/99, conhecida como Lei de Combate aos Crimes Eleitorais. De acordo com essa lei, é proibido a qualquer candidato "doar, oferecer, prometer ou entregar ao eleitor, com o fim de obter-lhe o voto, bens ou vantagem pessoal de qualquer natureza, inclusive emprego ou função pública". Todas essas ações e instituições da sociedade civil mostram elevada convergência com a cobrança da accountability.

Uma leitura que se pode fazer da tentativa da propositura de tais leis é que o processo eleitoral, tal como descreveu Campos em 1988, continua insuficiente para salvaguardar o interesse público. Em outras palavras, reconhece-se que o próprio cidadão brasileiro não é capaz de impedir que candidatos que não atuaram corretamente sejam reeleitos. Daí a busca por uma lei que impeça tal candidatura, ou seja, um mecanismo ex ante que favoreça a accountability. Não obstante, todos esses movimentos e ações evidenciam que nesses últimos 20 anos a sociedade civil brasileira se levantou do "berço esplêndido" e caminhou em direção à accountability. Necessário admitir, logicamente, que esse levantar e caminhar ainda ocorre de maneira tímida, lenta e, evidentemente, sofrendo todo tipo de bloqueio das forças conservadoras e retrógradas ligadas a uma sociedade no accountable.

\section{Sobre a descentralização e transparência governamental}

Compreendida como a movimentação de autoridade dos governos centrais para os governos locais, a descentralização é uma tendência nos governos democráticos. No Brasil, desde a reforma institucional, efetuada a partir da promulgação da Constituição Federal de 1988, que definiu os municípios como

\footnotetext{
${ }^{3}$ Disponível em: <www.mcce.org.br>. Acesso em: 16 jul. 2008.
} 
entes da federação, as instituições de governo local no Brasil têm passado por profundas transformações. Como nos lembra Santos Junior (2001), ao longo dos anos 1990 um conjunto de leis e políticas, federais e estaduais, deu prosseguimento a essa reforma gerando uma crescente transferência de responsabilidades e de competências dessas esferas para os governos locais. Observa-se, desde então, que cada vez mais os governos locais assumem maior autonomia e responsabilidades na gestão e execução de políticas públicas.

$\mathrm{O}$ que se espera desse processo de transferência é que possibilite o aprofundamento da democracia, a aproximação do cidadão das instâncias decisórias e contribua para que as políticas públicas sejam realizadas de forma mais eficiente e eficaz, afinal de contas, a priori, a visibilidade do representante torna-se maior no âmbito das municipalidades. Assim, a descentralização deve viabilizar também a transparência dos governos.

É salutar que se reconheça que medidas têm sido adotadas no sentido de fortalecer a democracia no poder local e, entre essas, destacamos a adoção do processo de elaboração do orçamento com a participação da sociedade, o chamado orçamento participativo (OP), a obrigatoriedade de criação de conselhos municipais para acompanhar e controlar a aplicação dos recursos recebidos, e da disposição das contas dos municípios para exame e apreciação por qualquer contribuinte. Oportuno esclarecer, de acordo com Dagnino (2004:96), que os OPs são espaços públicos derivados de escolhas políticas dos diferentes governos municipais e estaduais, onde a população discute e decide sobre o orçamento das suas administrações, ou seja, sobre onde e como os investimentos devem ser realizados. Cumpre salientar que ainda que existam críticas, e pertinentes, aos OPs, especialmente por conta das reduzidas margens de manobra na alocação de recursos do Poder Executivo, não há como negar que constituem aparatos de prática da exigência de accountability. A existência dos conselhos gestores decorre de uma exigência legal. De fato, tais conselhos materializam o exposto nos artigos da Constituição Federal, que estabelecem essa participação na saúde (inciso III, art. 198); na assistência social (inciso II, art. 204); e na educação (inciso VI, art. 206). Infelizmente, não são poucos os estudos que evidenciam a fragilidade desses conselhos, muito dos quais se limitam ao atendimento formal para viabilizar o recebimento dos recursos. Talvez seja nesse particular, na obrigatoriedade da criação dos conselhos versus a disposição favorável para instituir ou não o OP, que resida a explicação para o fato de que, diferentemente do que ocorreu com o OP, os conselhos tenham se disseminado por todos os municípios. Deve-se considerar, porém, que nesse contexto, o passo institucional já foi dado (criado o conceito) e este pode vir a ser aperfeiçoado ao longo do processo histórico. 
Outros fatos que merecem ser destacados são os da aprovação da Lei Complementar $n^{\circ}$ 101/2000, a conhecida Lei de Responsabilidade Fiscal (LRF); e a criação da Controladoria Geral da União (CGU), em abril de 2001. O primeiro instrumento impôs limites e condições para a gestão das receitas, despesas e quanto ao endividamento; exigiu a transparência das contas públicas e o planejamento como rotina na administração fiscal, bem como a responsabilização pelo seu descumprimento. Sacramento (2004) argumenta que, pelo menos no campo formal, a LRF contribui para que o processo de accountability avance no Brasil. A CGU, com funções administrativas de controle, correição, prevenção e ouvidoria, disponibiliza, via internet, informações sobre os valores de repasses de recursos federais destinados às instâncias subnacionais. Foi por meio de suas ações que tomamos conhecimento, por exemplo, que fraudes em licitações continuam sendo o problema mais comum entre as que são constatadas no programa de fiscalização por sorteios. É oportuno lembrar que a CGU provoca a atuação de órgãos importantes para a realização da dimensão de enforcement da accountability, fundamentais para a punição daqueles que transgridem as regras da res publica, tais como os tribunais de contas e o Ministério Público.

Autores como Anastasia e Melo (2002) reconhecem essas e outras iniciativas que ampliam a possibilidade de controle político pela cidadania organizada, tais como: o Siafi, sistema por meio do qual são obtidas as informações que subsidiam o balanço geral da União e os relatórios de execução do orçamento e de administração financeira que compõem a demonstração das contas apresentadas ao Congresso Nacional pelo presidente da República; o acesso, via internet, ao processo de transferências do FPE e do FPM (Fundo de Participação dos Estados e Fundo de Participação dos Municípios); as TVs e as rádios da Câmara e do Senado; a criação de ouvidorias; a criação da Comissão de Legislação Participativa, com poderes para acolher e transformar em proposição legislativa sugestões apresentadas por associações e órgãos de classe, sindicatos e entidades organizadas da sociedade civil ou pareceres técnicos, exposições e propostas oriundas de entidades científicas e culturais; e a modificação do art. 53 da CF, em dezembro de 2001, dando nova redação à questão da imunidade parlamentar e tornando os deputados e senadores passíveis de processo pelo Supremo Tribunal Federal sem a necessidade de licença prévia da Casa.

Observa-se que mesmo o Poder Judiciário, que Grau (2006) admite como um dos mais difíceis no qual empreender reformas na América Latina, não ficou imune ao debate quanto à necessidade de transparência e controle. Prova disso é a Emenda Constitucional no 45, de 31 de dezembro de 2004, por 
meio da qual foi criado o Conselho Nacional de Justiça (CNJ) órgão competente para controlar a atuação administrativa e financeira do Poder Judiciário e o cumprimento dos deveres funcionais dos juízes. Entre suas atribuições consta, por exemplo, a de receber reclamações contra membros ou órgãos do Judiciário, inclusive contra seus serviços auxiliares, serventias e órgãos prestadores de serviços notariais e de registro que atuem por delegação do poder público ou órgãos oficializados. Outra inovação é a TV do Poder Judiciário, no ar desde 2002, transmitindo julgamentos, programas de debates, seminários etc. ${ }^{4}$

Constata-se, pois, que muitas alterações foram processadas no que se refere à descentralização e transparência nos últimos 20 anos. Se, por um lado, ainda não se pode afirmar que o véu da administração pública brasileira tenha sido retirado por completo, por outro, se deve reconhecer que o cenário do momento presente é completamente distinto do vivenciado por Campos (1975-1988) ensejando um aumento de accountability ou pelo menos criando algumas condições para isso.

\section{Sobre a substituição de valores tradicionais por valores sociais emergentes}

Outro pilar considerado por Campos para a emergência da accountability refere-se à substituição de valores tradicionais por novos valores, o que encontra abrigo nos estudos da cultura política. Segundo Krushnir e Carneiro (1999), cultura política é o conjunto de atitudes, crenças e sentimentos que dão ordem e significado a um processo político, evidenciando as regras e pressupostos que orientam o comportamento de seus atores.

Ao se analisar o ambiente político brasileiro, à luz dessa definição, compreende-se o porquê de vários estudiosos considerarem a existência de certa dualidade na natureza da nossa cultura política (por exemplo: Avritzer, 1995; Baquero, 2003; Martins, 1997; Pinho, 1988; Santos, 1993). Admite-se nessa literatura, de maneira geral, que há uma situação paradoxal na América Latina, ou seja, ao mesmo tempo em que traços da "arquitetura institucional da democracia" (Diniz, 2001:16) são adotados (liberdade de expressão e organização, eleições livres e idôneas, entre outros), traços políticos convencionais, como clientelismo, paternalismo, patrimonialismo e personalismo prevalecem,

\footnotetext{
${ }^{4}$ Disponível em: <www.tvjustica.jus.br>. Acesso em: 16 jul. 2008.
} 
resultando numa cultura política na qual o interesse individual se sobrepõe ao interesse coletivo.

É a prevalência desses traços tradicionais que motiva O’Donnell (1988) a considerar a democracia da América Latina como um tipo particular de democracia e a adjetivá-la como "delegativa", isto é, situação na qual ocorrem eleições livres, mas o vencedor do processo eleitoral está autorizado a governar da maneira que lhe parecer conveniente, não necessitando atuar em conformidade com o prometido durante a campanha eleitoral. Em outras palavras, sacrificando a accountability. Nesse ponto convém destacar que Coelho (2000), ao analisar os resultados de uma survey realizada em 1998, concluiu que os brasileiros preferem a democracia a qualquer outro tipo de governo, mas se necessário, aceitam o recurso do líder autoritário.

Cumpre informar que essa imperfeição da democracia brasileira tem se confirmado em estudos desenvolvidos na atualidade. Exemplo disso é o estudo desenvolvido pelo The Economist (2006), ${ }^{5}$ no qual cinco categorias gerais são estabelecidas (processo eleitoral e pluralismo, funcionamento do governo, participação política, cultura política e liberdade civil) para análise de 167 países, classificando seus regimes em: democracia completa (full democracies); democracia imperfeita (flawed democracies); regime híbrido (hybrid regimes); e regime autoritário (authoritarian regimes). Verifica-se nesse estudo que o Brasil alcançou alto score na análise do processo eleitoral e liberdade civil (9,58 e 9,41, respectivamente), mas os índices obtidos nas categorias funcionamento do governo $(7,86)$, participação política $(4,44)$ e cultura política $(5,63)$ levam-no a ocupar a $42^{a}$ posição, estando enquadrado na situação de democracia imperfeita (flawed democracies), atrás de outros latinos americanos (Chile, 30; ; Uruguai, 27a; e Costa Rica, 25a). Observa-se que os dois últimos fatores (participação política e cultura política) são aqueles identificados por Campos como carências, o que confirma que nesses quesitos houve pouco avanço ou nenhum nos últimos 20 anos.

Outro estudo que não pode deixar de ser mencionado é o desenvolvido por Almeida (2007). Buscando compreender "a cabeça do brasileiro", ele conclui que no Brasil coexistem dois países, cujas mentalidades, comandadas pela educação, são bastante distintas: uma moderna, outra arcaica. De acordo com o autor, "o Brasil é hierárquico, familista, patrimonialista e aprova tanto o jeitinho quanto um amplo leque de comportamentos similares". Não obstante, as evidências indicaram que esses valores se enfraquecem em grupos sociais

${ }^{5}$ Disponível em: <www.economist.com>. Acesso em: 26 jul. 2008. 
com nível de escolaridade mais elevado. Daí o otimismo do autor ao depreender que "como a escolaridade está aumentando, pode-se esperar que no futuro haja mais modernos do que arcaicos" (Almeida, 2007:19).

Voltando à resistência das práticas relacionadas ao patrimonialismo no Brasil, Simon Schwartzman, na década de 1980, cria o conceito de neopatrimonialismo (Schwartzman, 1988) para definir a sociedade brasileira contemporânea que em sua perspectiva não seria nem uma sociedade plenamente industrial, nem uma sociedade moderna. Em outras palavras, mesmo a dinamização da industrialização e outros elementos da modernidade não foram capazes de erradicar o patrimonialismo, configurando, no entanto, essa versão neopatrimonialista onde convivem o moderno e o tradicional.

Na literatura que diagnostica o patrimonialismo da cultura política brasileira é comum relacioná-lo à origem lusitana desse Estado. Martins (1997:14), por exemplo, converge com esse diagnóstico ao afirmar que o Estado e a administração pública já nasceram patrimonialistas. De igual forma, para Keith Rosen (apud Barbosa 1992:22), o passado português ainda condiciona as atitudes brasileiras em relação ao funcionamento do governo, tais como a tolerância com a corrupção e a baixa expectativa de serviço público honesto, caminhando paralelamente com a persistência da ausência de accountability.

Essa situação tem, por sua vez, origem nos interesses do que Faoro (1979) chama de estamento, grupo que controla o Estado e tem sido resistente às transformações fundamentais à modernização mantendo um "capitalismo politicamente orientado". Essa "variante" do capitalismo, para usar uma expressão de Nunes (2003:25), adotou do capitalismo moderno a técnica, as máquinas e as empresas, sem, contudo, aceitar a racionalidade impessoal e legal-universal, garantiu a imutabilidade histórica do patrimonialismo no Estado brasileiro. Nas palavras de Faoro, "deitou-se remendo de pano novo em vestido velho, vinho novo em odres velhos, sem que o vestido se rompesse, nem o odre rebentasse" (Faoro, 1979:733-748).

Observa-se que a incapacidade brasileira para a realização de grandes rupturas com o tradicional costuma ser destacada em diversos estudos que abordam momentos marcantes da nossa história. Além das análises supracitadas, a reflexão trazida por Lessa (2001) sobre o processo "sem traumas e disrupções" da nossa independência também se constitui num interessante exemplo. Segundo esse autor, a preservação da estrutura colonial revela a natureza conservadora do movimento pela independência brasileira, que "transmutou um Bragança - herdeiro da Coroa Portuguesa - em Imperador do Brasil" (Lessa, 2001:246). 
Tal característica não passou despercebida na análise feita por Ianni (1994), quando este afirma que "[o] Brasil não é propriamente uma nação", mas configura-se, desde o Império e ao longo da República, como "uma vasta desarticulação" (Ianni; 1994:177-178). "Não parece uma nação o país em que a população ainda não se tornou povo", como continua presente nos vários estudos sobre as recentes reformas promovidas na administração pública brasileira. Pinho (1998), por exemplo, ao discutir a possibilidade da reforma do Estado no sentido de implantar a administração gerencial, mostra as dificuldades dessa ação por conta da existência dos interesses e valores patrimonialistas na realidade brasileira, que se caracteriza por "uma história de acumulação de fenômenos onde não ocorre ruptura, onde o novo se amolda ao velho e, dialeticamente, o velho se amolda ao novo" (Pinho, 1988:76). Tal constatação somente fortalece o quadro interpretativo da realidade brasileira sugerido por Nogueira (1998) que, admitindo a natureza híbrida e diádica do Estado brasileiro, considera-o do tipo burocrático enxertado de patrimonialismo, marcado por uma heterogeneidade congênita que dificulta a plena generalização da eficácia e da eficiência em seu interior. Esse Estado, segundo o mesmo autor, provavelmente tenha se convertido em espaço e instrumento de conciliações intermináveis, não pôde se tornar completamente moderno e autenticamente republicano, nem deixar de se submeter a práticas e concepções fortemente vinculadas ao tradicional privatismo das elites:

Nossa burocracia, por exemplo, não rompeu com as formas patrimoniais derivadas da ordem colonial e reproduzidas pela ordem republicano-oligárquica que precedeu a industrialização. (...) Ao invés disso, a burocracia sempre esteve vinculada aos interesses societais, sendo invariavelmente capturada por eles ou por eles envolvida. Esteve imersa em um processo no qual domínio público e domínio privado se interpenetravam, no qual a gestão política apresentava-se como assunto de interesse particular dos funcionários e não como assunto pertinente ao campo dos interesses objetivos.

(Nogueira, 1998:204)

Aceitos esses argumentos, não é de espantar que condições mais estruturais sejam difíceis de serem vencidas em um período curto de tempo, 20 anos no caso. Em verdade, o que se observa nas últimas duas décadas é a convivência de um processo de mudança de valores no Brasil que favorecem a accountability, expressos nos vários movimentos anteriormente mencionados (CGU, OP, conselhos, ONGs ligadas à transparência, papel da imprensa etc.) com os valores que a dificultam, os mais tradicionais, e que ainda mostram 
muita exuberância e capacidade de articulação, reforçando a ideia de que o Brasil "não é monolítico, mas uma sociedade dividida entre o arcaico e o moderno" (Almeida, 2007:275).

\section{E afinal, podemos traduzir accountability?}

Este trabalho teve como objetivo central verificar se as alterações políticas, sociais e institucionais contribuíram para que a tradução da palavra accountability germinasse no solo brasileiro, passados 20 anos da elaboração do artigo seminal de Anna Maria Campos, "Accountability: quando poderemos traduzi-la para o português?" e se, assim, o termo já poderia ser traduzido para o português. Buscando o significado da palavra accountability em dicionários, justamente para apreender com maior precisão o que o termo significa em inglês e como tem sido traduzido para o português, constatou-se que o significado do conceito envolve responsabilidade (objetiva e subjetiva), controle, transparência, obrigação de prestação de contas, justificativas para as ações que foram ou deixaram de ser empreendidas, premiação e/ou castigo.

Ao observar as alterações políticas, sociais e institucionais ocorridas no Brasil nesses 20 anos constata-se que, embora muitos passos importantes tenham sido dados em direção à accountability, com criação de novas instituições, fortalecimento institucional em geral, a caminhada promete ser longa, principalmente porque ficou caracterizado que no Brasil o surgimento de um novo valor não necessariamente implica extinção do tradicional. Parece haver uma impressionante capacidade de superação da ordem legal muitas vezes, com extrema criatividade e inventividade, para fazer valer a velha ordem. $\mathrm{O}$ autoritarismo tem mostrado uma enorme capacidade de se redesenhar, se redefinir diante das mudanças institucionais e culturais a favor do aumento de accountability. Em um breve passeio pelo texto de Campos, podemos colher alguns termos que não foram extintos da realidade brasileira, ainda que tenham sofrido certa transfiguração, tais como sociedade passiva, nepotismo, favoritismo, privilégios para alguns/poucos, falta de participação da sociedade civil, autoritarismo, populismo, crise de credibilidade das instituições, principalmente o Congresso, o padrão casuístico dos partidos políticos, troca de votos por cargos públicos e um enorme etc. Como dito supra, muitos desses elementos têm sido enfrentados por um novo posicionamento da sociedade civil e do próprio aparato governamental, oferecendo uma dose de otimismo comedido. É lógico que superamos o regime autoritário dos militares, com todas as suas mazelas, mas continuam a aflorar problemas estruturais da nos- 
sa formação histórica que podem nos levar a um fundado pessimismo. Mais grave ainda do que a afirmação de Campos quanto à falta do conceito de accountability, vimos que para Ianni (1994) ainda nos falta o conceito de nação. Nesse sentido, o Brasil seria "uma nação em progresso" que busca "transformar-se em conceito".

Para sintetizar, mostra-se difícil dar uma resposta conclusiva à questão formulada neste artigo. Avanços têm sido realizados, páginas têm sido viradas na história brasileira, mas mudanças de maior fôlego, de caráter estrutural são difíceis de ser dadas em um curto período de tempo (20 anos), quando se enfrentam forças e culturas conservadoras encasteladas há séculos com capacidade de adequação e de transformação às novas realidades. Não querendo fugir da resposta, podemos dizer que estamos mais perto da tradução do que quando Campos se defrontou com a questão, mas ainda muito longe de construir uma verdadeira cultura de accountability. Fechando com palavras otimistas, esse conceito está em construção, assim como o de nação, e dentro dos parâmetros da democracia como valor universal, o que não é pouco para uma longa tradição de autoritarismo.

\section{Referências}

ABRÚCIO, Fernando Luiz. Responsabilização pela competição administrada. In: BRESSER-PEREIRA, Luiz Carlos; GRAU, Nuria Cunill (Coords.). Responsabilização na administração pública. São Paulo: Clad/Fundap, 2006.

ALMEIDA, Alberto Carlos. A cabeça do brasileiro. Rio de Janeiro: Record, 2007.

ANASTASIA, Fátima; MELO, Carlos Ranulfo F. Accountability, representação e estabilidade política no Brasil. O Estado numa era de reformas: os anos FHC (parte 1). Coleção Gestão Pública, Brasília, v. 7, p. 25-74, 2002.

AVRITZER, Leonardo. Cultura política, atores sociais e democratização. Uma crítica às teorias da transição para a democracia. Revista Brasileira de Ciências Sociais, São Paulo, n. 28, p. 109-122, jun. 1995.

. O orçamento participativo: as experiências de Porto Alegre e Belo Horizonte. In: DAGNINO, Evelina (Org.). Sociedade civil e espaços públicos no Brasil. São Paulo: Paz e Terra, 2002.

BAQUERO, Marcello. Construindo outra sociedade: o capital social na estruturação de uma cultura política participativa no Brasil. Revista de Sociologia e Política, Curitiba, n. 21, p. 83-108, 2003. 
BARBOSA, Lívia. O jeitinho brasileiro. Rio de Janeiro: Campus, 1992.

BRESSER-PEREIRA, Luiz Carlos. Sociedade civil: sua democratização para a reforma do Estado. In: BRESSER-PEREIRA, Luiz Carlos; WILHEIM, J.; SOLA, L. (Orgs.). Sociedade e Estado em transformação. São Paulo: Unesp/Enap, 1999.

. As formas de responsabilização na gestão pública. In: BRESSER-PEREIRA, Luiz Carlos; GRAU, Nuria Cunill (Coords.). Responsabilização na administração pública. São Paulo: Clad/Fundap, 2006.

CAMPOS, Anna Maria. Accountability: quando poderemos traduzi-la para o português? Revista de Administração Pública, Rio de Janeiro, fev./abr. 1990.

CARVALHO, José Murilo de. Cidadania no Brasil: o longo caminho. Rio de Janeiro: Civilização Brasileira, 2008.

Clad (Centro Latino-americano de Administração para o Desenvolvimento). A responsabilização na nova gestão pública latino-americana. In: BRESSER-PEREIRA, Luiz Carlos; GRAU, Nuria Cunill (Coords.). Responsabilização na administração pública. São Paulo: Clad/Fundap, 2006.

COELHO, Maria Francisca Pinheiro. O gosto pela política. In: ARAÚJO, Caetano Ernesto Pereira de et al. (Orgs.). Política e valores. Brasília: Universidade de Brasília, 2000.

DAGNINO, Evelina. Sociedade civil e espaços públicos no Brasil. São Paulo: Paz e Terra, 2002.

. Sociedade civil, participação e cidadania: de que estamos falando? In: MATO, Daniel (Coord.). Políticas de ciudadania y sociedad civil em tiempos de globalizacion. Caracas: Faces, Universidad Central de Venezuela, 2004.

DINIZ, Eli. Globalização, reforma do Estado e teoria democrática contemporânea. São Paulo em Perspectiva, São Paulo, v. 15, n. 4, out./dez. 2001.

FAORO, Raimundo. Os donos do poder. A formação do patronato brasileiro. 5. ed. Porto Alegre: Globo, 1979.

GRAU, Nuria Cunill. Responsabilização pelo controle social. In: BRESSER-PEREIRA, Luiz Carlos; GRAU, Nuria Cunill (Coords.). Responsabilização na administração pública. São Paulo: Clad/Fundap, 2006.

KUSCHNIR, Karina; CARNEIRO, Leandro Piquet. As dimensões subjetivas da política: cultura política e antropologia da política. Revista Estudos Históricos, Rio de Janeiro, v. 13, n. 24, 1999. Disponível em: <www.cpdoc.fgv.br>. Acesso em: 25 abr. 2008.

LEARNER'S dictionary of current english. Oxford: Oxford University Press, 1978. 
LESSA, Carlos. O parto sem dor do Estado nacional brasileiro e com muita dor da economia nacional. In: MEDEIROS, Carlos; FIORI, José Luis. Polarização mundial e crescimento. Petrópolis: Vozes, 2001.

MARTINS, Luciano. Reforma da administração pública e cultura política no Brasil: uma visão geral. Cadernos Enap, Brasília, n. 8, p. 8-56, 1997.

MELO, Marcus André. O viés majoritário na política comparada: responsabilização, desenho institucional e qualidade democrática. Revista Brasileira de Ciências Sociais, São Paulo, v. 22, n. 63, 2007.

MERRIAN-WEBSTER'S COLLEGIATE DICTIONARY. 10. ed. Springfield, MA: Merrian-Webster, Inc., 1996.

MICHAELIS. Dicionário prático inglês-português/português-inglês. São Paulo: Melhoramentos, 1988.

MOTA, Ana Carolina Yoshida Hirano Andrade. Accountability no Brasil: os cidadãos e os seus meios institucionais de controle dos representantes. Tese (Doutorado) — USP, São Paulo, 2006.

NOGUEIRA, Marco Aurélio. As possibilidades da política: ideias para a reforma democrática do Estado. São Paulo: Paz e Terra, 1998.

NUNES, Edson. A gramática política do Brasil: clientelismo e insulamento burocrático. 3. ed. Rio de Janeiro: Jorge Zahar/ENA, 2003.

O'DONNELL, Guillermo. Democracia delegativa? Novos Estudos, São Paulo, n. 31, p. 25-40, out. 1991.

. Accountability horizontal e novas poliarquias. Lua Nova, São Paulo, n. 44, p. 27-52, 1998.

IANNI, Octávio. A ideia de Brasil moderno. São Paulo: Brasiliense, 1994.

OXFORD ADVANCED LEARNER'S DICTIONARY. Oxford: Oxford University Press, 2005.

PINHO, José Antonio Gomes de. Reforma do aparelho do Estado: limites do gerencialismo frente ao patrimonialismo. Revista Organizações \& Sociedade, Salvador, n. 12 , p. 59-79, 1998.

PRZEWORSKI, Adam. Sobre o desenho do Estado: uma perspectiva agent $x$ principal. In: BRESSER-PEREIRA, Luiz Carlos; SPINK, P. (Orgs.). Reforma do Estado e administração pública gerencial. Rio de Janeiro: FGV, 1998.

ROGET'S thesaury. Hammondsworth, England: Penguin Books Ltd., 1962. 
SACRAMENTO, Ana Rita S. Lei de responsabilidade fiscal, accountability e cultura política do patrimonialismo: um estudo exploratório em seis municípios da Região Metropolitana de Salvador. Dissertação (Mestrado) — NPGA/EAUFBA, Salvador, 2004.

SANTOS JUNIOR, Orlando Alves do. Democracia e governo local: dilemas e reforma municipal no Brasil. Rio de Janeiro: Revan, 2001.

SANTOS, Boaventura de Sousa. A gramática do tempo: por uma nova cultura política. São Paulo: Cortez, 2006.

SANTOS, Wanderley Guilherme dos. Razões da desordem. Rio de Janeiro: Rocco, 1993.

SCHEDLER, Andreas. Conceptualizing accountability. In: SCHEDLER, A.; DIAMOND, L.; PLATTNER, M. F. (Eds.). The self-restraing state. Power and accountability in new democracies. Boulder and London: Lynne Rienner Publishers, 1999.

SCHWARTZMAN, Simon. Bases do autoritarismo brasileiro. Rio de Janeiro: Campus, 1988. Disponível em: <www.schwartzman.org.br>. Acesso em: 20 jun. 2008.

SORJ, Bernardo. Sociedade civil e política no Brasil. In: SEMINÁRIO SOCIEDADE CIVIL E DEMOCRACIA NA AMÉRICA LATINA: CRISE E REINVENÇÃO DA POLÍTICA. Anais... Instituto Fernando Henrique Cardoso e Centro Edelstein de Pesquisas Sociais, São Paulo, 2006. Disponível em: <www.ifhc.org>. Acesso em: 4 abr. 2008.

TROSA, Sylvie. Gestão pública por resultados: quando o Estado se compromete. Brasília: Enap, 2000.

VALLANDRO, Leonel; VALLANDRO, Lino. Dicionário inglês-português. Porto Alegre: Globo, [s.d.]. 